This item was submitted to Loughborough's Research Repository by the author.

Items in Figshare are protected by copyright, with all rights reserved, unless otherwise indicated.

\title{
The impact of inclusiveness on resilience in Temporary Multidisciplinary Organizations (TMO)
}

PLEASE CITE THE PUBLISHED VERSION

https://doi.org/10.1061/9780784481295.025

\section{PUBLISHER \\ (C) ASCE}

VERSION

AM (Accepted Manuscript)

\section{PUBLISHER STATEMENT}

This work is made available according to the conditions of the Creative Commons Attribution-NonCommercialNoDerivatives 4.0 International (CC BY-NC-ND 4.0) licence. Full details of this licence are available at: https://creativecommons.org/licenses/by-nc-nd/4.0/

\section{LICENCE}

CC BY-NC-ND 4.0

\section{REPOSITORY RECORD}

Blay, Karen B.. 2019. "The Impact of Inclusiveness on Resilience in Temporary Multidisciplinary Organizations (TMO)”. figshare. https://hdl.handle.net/2134/28086. 


\title{
The impact of inclusiveness on resilience in Temporary Multidisciplinary Organizations (TMO)
}

\author{
Karen BLAY ${ }^{1}$ \\ ${ }^{1}$ School of Architecture, Building and Civil Engineering, Loughborough University, \\ Loughborough. United Kingdom. LE11 3TU PH (0044) 1509 228740; email: \\ k.b.blay@lboro.ac.uk
}

\begin{abstract}
One of the enablers of organizational resilience is inclusiveness. Inclusiveness is the process of valuing, respecting and supporting members of an entity. Resilience in permanent organizations can be defined as the capability to respond to and prepare for disruption and thus, promote business continuity. On the other hand, resilience in Temporary Multidisciplinary Organizations (TMO) can be defined as the capability to respond to, prepare for and reduce the impact of disruptions caused by the drifting environment and complexity. A construction project can be viewed as a TMO. The time-limit and contract-focus of TMO challenges inclusiveness and hence makes its impact on resilience in TMO, unclear. Given the dynamic nature of TMOs (highly susceptible to disruptions), there is the need to identify the impact of inclusiveness, thus, the aim of this research. Using a case study approach (two case studies) and critical incident technique, it was identified that the TMO in which inclusiveness was actively promoted responded better to disruptions. This was enabled by project managers, directors and the project execution plan. The identified impact of inclusiveness in managing disruptions were; time and cost savings, innovation and quality enhancement. These findings contribute to debates on disruption management in TMOs (projects).
\end{abstract}

Keywords: inclusiveness, resilience, capability, disruption, Temporary Multidisciplinary Organization (TMO)

\subsection{INTRODUCTION}

TMOs experience disruptions beyond the normal control. These disruptions are caused by the drifting environment (Kreiner 1995) and complex nature (Qazi et al. 2016; Baccarini 1996) of TMOs. Like permanent organizations, diverse approaches have been put in place in TMOs to manage disruptions comprising, risk, uncertainty, change and crisis management. These approaches are limiting due to its focus on predicting hazards and incorporating measures to manage them in order to reduce vulnerability. This prevents the TMOs from identifying and developing capabilities to enable disruptions especially the unknown causes to be managed to ensure recovery which encompasses response, readiness and vulnerability reduction. This has therefore led to the introduction of the concept of resilience in TMO which can be defined as the capability to respond to, prepare for and be ready to manage disruptions caused by complexity and drifting environment. This concept ensures 
recovery through capabilities such as proactivity, coping ability, flexibility and persistence.

However, the manifestation of capabilities to manage disruptions in TMOs is affected by inclusiveness. Inclusiveness can be defined as the process of valuing, respecting and supporting members of an entity (Ryan 2008). This concept of inclusiveness within organizations is adopted from the concept of 'sense of belonging' in resilience in children (Bernard 1994, 2004; Pearson n.d). Within permanent forms of organizations, inclusiveness is identified to ensure cost and time savings during disruption management. Resilience as employed in permanent organizations is also referred to as organizational resilience and utilizes capabilities to respond to and prepare for disruption and thus, promote business continuity (Mcmanus 2008).

The temporality in TMOs however makes the exact impact of inclusiveness when managing disruptions unclear. Thus, the aim of this research is to identify the impact of inclusiveness on resilience in TMO. This research contributes to debates in construction management success (for example Lin and Pathranarakul 2006; Vacanasa et al. 2015) and disruption management in projects (Gibson 2015). To attain this, a review of impact on inclusiveness in organizational resilience is explored together with highlighting the little research on the impact of inclusiveness in TMO. Furthermore, data is collected by employing a case study approach and Critical Incident Technique (CIT) and findings discussed and results presented.

\subsection{INCLUSIVENESS IN ORGANIZATIONAL RESILIENCE}

Organizational resilience employs a less directive management style, a more collaborative decision making approach and an inclusive environment (Seville et al. 2006). This is because, for innovation and business continuity to be achieved whilst managing disruptions, an inclusive environment where one feels valued, respected and supported is required (Yilmaz et al. 2015). Exclusion in permanent organization is generally to females (Pateman 2014), minority (Janssens and Zanoni 2014) and non-managers. Since organizational resilience is based on situational awareness, it seeks to consider information from everyone irrespective of the race and gender in order to motivate them to be committed and thus feel included. Authors such as Lok et al. (2005) measure inclusiveness by the level of commitment of organizational members.

Resilient organizations value its members by listening to their ideas and contributions towards situational awareness and reward them (Yilmaz et al. 2015). It also promotes respect through equal treatment irrespective of background and utilize a subtle tone when correcting members (Vogus and Sutcliffe 2007; Kahn et al. 2013). In terms of support, it is achieved through social and financial means such as mentoring and monetary bonuses (Sutcliffe and Vogus 2003) respectively. These develop the competencies of the members of the organization and are motivated to manage disruptions (Sutcliffe and Vogus 2003). These manifestations of inclusiveness promote the innovation and learning antecedents of organizational resilience. 
Given the temporality and structural difference of TMOs, the antecedents to and consequence for value, respect and support for organizational resilience is incoherent, as such this research identifies the impact of inclusiveness in resilience in TMOs. Unlike resilience in permanent organizations, where inclusiveness is determined by the level of commitment, TMOs operate differently. Within TMOs, though organizations come together to execute the task, they have close ties with their parent organizations and tend to be inclusive at the parent organization level instead. Also, TMOs are challenged with knowledge sharing given the possibility to compete in future for other works hence the challenge on increasing situational awareness as per organizational resilience. Given the impact of inclusiveness in organizational resilience, it is also essential to identify its impact on resilience in TMOs also.

\subsection{THE ROLE OF INCLUSIVENESS IN RESILIENCE IN TMOS: THE NEED FOR FURTHER RESEARCH}

Resilience in TMOs can be defined as the capability to respond to, prepare for and reduce the impact of disruption caused by the drifting environment and TMO complexity. The capabilities include proactivity, coping ability, flexibility and persistence. Proactivity enables disruptions to be managed through contractual relationship, training, monitoring, contingency and experience whilst coping ability enables disruption management by focusing on adjusting through psychological coping (responsibility coping, regulative coping). Responsibility coping is defined as a role driven approach of coping whereby one accepts responsibility in putting things right whereas regulative coping is the ability to manage and deal with stress by controlling ones feeling and attitude towards a critical incident. Furthermore, flexibility enables disruption management by allowing change but ultimately making sure that the aim is maintained. That is, it provides an ability to adjust to change and promotes renewal and development. Within TMOs, flexibility is mainly manifested through understanding and promotion of innovation. Lastly, TMOs persist by focussing on its entire working ability to ensure that the endeavour is completed irrespective of objective met, once it works towards meeting the ultimate goal. It is promoted by project management procedures such as continual monitoring (as per risk management and innovativeness), continual planning and negotiations.

Following the above, inclusiveness as highlighted by Sutcliffe and Vogus (2003) and Vogus and Sutcliffe (2007) motivates organizations to maximize its capabilities however, these refer to permanent organizations, as such the exact impact in Temporary forms of organizations is unclear. Also, to manage disruptions, it is essential to utilize organizational capabilities which can be achieved when the team are and feel included. Using impact of inclusiveness in organizational resilience as a lens, the conceptual framework (Figure 1) below highlights the need to identify the impact of inclusiveness on resilience in TMOs and thus answer the question; what impact does inclusiveness have on resilience in TMO? 


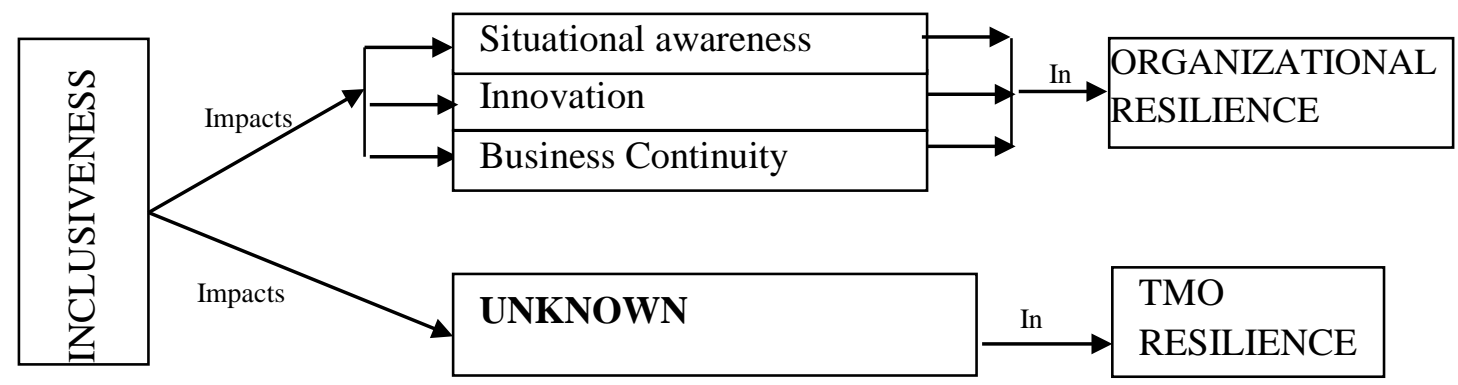

Figure 1 Conceptual framework for the impact of inclusiveness on resilience

\subsection{RESEARCH METHODOLOGY}

To identify the impact of inclusiveness, resilience in TMOs is observed. Within this research, inclusiveness, if present, is identified when TMOs utilize capabilities to respond to, prepare for and reduce the impact of disruptions caused by its complexity and the drifting environment, as such critical incidents are studied. Critical incidents are unexpected (uncertain) occurrence which is outside the planned works and causes distress (Flanagan 1954) and hence enable the identification of the impact of inclusiveness. Also, to identify inclusiveness, a close contact with the TMOs is required in order to extract the consequence of inclusiveness through observations, document analysis and interviews. Therefore, a case study approach is employed. The unit of analysis for this research is the TMO and sub-unit is critical incident.

\subsection{Case study details}

Complex TMOs were targeted due to the extra management processes such as planning, monitoring and expense they require (Fiori and Kovaka 2005). The TMOs were located in the midlands and southern part of the United Kingdom. These comprize a building and civil engineering project. Case study 1 is an educational building, comprized of a laboratory and associated teaching space. Case study 2 is a new build structural extension to a bridge.

\subsection{Data collection and analysis}

The case studies commenced with archival data analysis of high level strategic documents composed of project management procedures and mechanism and observations comprising managerial level meetings and presentations for the way forward following a critical incident. Each case study lasted for three months and it was carried out from July to December 2016. Both archival data analysis and observation continued till the end of the case studies. After establishing enough rapport with key participants, good understanding of the works and key issues, interviews were conducted to identify the impact of inclusiveness on resilience. From case study 1- (building project), 13 respondents were interviewed and case study 2- 
(civil engineering) had 8 respondents. The interviewees comprized architects, project managers (consultant and contractor), quantity surveyors, mechanical engineer, client, project director, operations manager and design manager. A minimum of one hour interview per respondent was conducted and interview questions sought specific information on capabilities manifested during disruptions and evidence and impact of inclusiveness. During the interviews, after respondents answered questions on capabilities employed, subsequent questions on inclusiveness were asked to assess its impact on capabilities.

Data from the case studies was analysed using Nvivo10. The data acquired was analysed under emerging themes which were the capabilities. Under each capability two sub-nodes were created, one for evidence of inclusiveness and the other for non-inclusiveness. The impact of inclusiveness or non-inclusiveness in manging disruptions were deduced from responses and summarized in Table 1.

\subsection{FINDINGS}

From the case studies, the main objectives of the TMOs were to complete the works, on time, within cost and quality. However, it was highlighted that the manifested disruptions challenged this from occurring. Hence, the earlier disruptions were managed, the quicker the ability to achieve objectives. Table 1 summarizes the impact of inclusiveness on resilience identified from case studies 1 and 2. 


\section{Table 1 Impact of inclusiveness on resilience in TMO}

\begin{tabular}{|c|c|c|}
\hline $\begin{array}{l}\text { Capabilities to manage } \\
\text { disruptions/ Dimensions of } \\
\text { Resilience }\end{array}$ & $\begin{array}{l}\text { Impact of inclusiveness on } \\
\text { Resilience-Case Study } 1\end{array}$ & $\begin{array}{l}\text { Impact of less-inclusiveness } \\
\text { on Resilience-Case Study } 2\end{array}$ \\
\hline Proactivity & $\begin{array}{l}\text { Clarity, Trust, Coordination, } \\
\text { Unveil hidden traits required to } \\
\text { manage critical incident }\end{array}$ & $\begin{array}{l}\text {-Redesign of works twice } \\
\text { during disruptions in order to } \\
\text { respond to disruptions }\end{array}$ \\
\hline \multirow[t]{4}{*}{ Coping ability } & $\begin{array}{l}\text {-Enables endurance by the overall } \\
\text { team to ensure readiness and } \\
\text { reduction }\end{array}$ & $\begin{array}{l}\text {-Increase cost of re-doing } \\
\text { works }\end{array}$ \\
\hline & $\begin{array}{l}\text {-Motivation to promote innovation } \\
\text { and ensure response }\end{array}$ & \\
\hline & $\begin{array}{l}\text {-Promote experience sharing to } \\
\text { ensure readiness and reduction }\end{array}$ & \\
\hline & $\begin{array}{l}\text {-Promote tolerance and adjusting to } \\
\text { ensure response and vulnerability } \\
\text { reduction whilst maintaining } \\
\text { quality requirement }\end{array}$ & \\
\hline Flexibility & $\begin{array}{l}\text {-Adopting alternative unplanned } \\
\text { innovative solutions whilst } \\
\text { maintaining quality requirement to } \\
\text { ensure response }\end{array}$ & $\begin{array}{l}\text { Lack of trust amongst the } \\
\text { team and little maximization } \\
\text { of time }\end{array}$ \\
\hline Persistence & $\begin{array}{l}\text {-Promote continual monitoring to } \\
\text { identify disruptions in order to } \\
\text { ensure readiness and reduction }\end{array}$ & $\begin{array}{l}\text { Less empowered team at the } \\
\text { onset and more control for the } \\
\text { TMO leaders mainly }\end{array}$ \\
\hline
\end{tabular}

From the findings, case study 1 showed evidence of value, support and respect within the TMO hence managed disruptions without introducing more disruptions and misunderstandings within the TMO unlike case study 2 which faced challenges as a result of the exclusion approach it employed. In comparison to case study 1, case study 2 promoted less inclusiveness whilst managing disruptions. Despite the manifestations of similar capabilities to case study 1, the TMO in case study 2 did manage disruptions but after being delayed, increase in cost and reduced quality.

In addition, during the disruption, inclusiveness had a positive impact on the TMO. For instance, case study 1 revealed that inclusiveness which was enabled by project managers, directors and the project execution plan made everyone have a sense of belonging. Inclusiveness in case study 1 better enabled proactivity and led to the resolution of disruption without incurring extra cost and at the minimal time 
possible. Also, inclusiveness in case study 1 enabled coping ability, flexibility and persistence and led to overall TMO time saving and increase innovations during the disruptions. The impact of less-inclusiveness in case study 2 during disruption management led to delay even whilst being proactive and reduction in quality whilst coping with the disruptions. Also, the less inclusiveness in case study 2 led to a delay in signing the contract even when being flexible and cost and time increase whilst being persistence.

The reason for less-inclusiveness in case study 2 was due to a directive management approach employed within the TMO. The client within the TMO was labelled as an intelligent client and therefore hardly listened to the rest of the team and focused little on supporting, valuing and respecting the TMO. The main focus was to complete the works with members of the TMOs carrying out their respective roles as per the contract. Furthermore, the client highlighted the insufficiency of time allowed for the works therefore required the team to be hands on without taking time out to ensure value, support and respect. It was also observed that, more new members were employed in case study 2 as compared to case study 1 . This was not as a result of lack of expertise as the reason for personnel change in case study 1 but is as a result of less value, support and respect experienced whilst managing disruptions. In hindsight, despite case study 2 ruling out inclusiveness to save time, it rather delayed managing disruption, increased cost and led to less innovation.

\subsection{DISCUSSION OF FINDINGS}

From the findings, a positive relationship between inclusiveness and resilience in TMOs is identified. Also, the findings show that the impact of inclusiveness on resilience in permanent organizations largely differs from TMOs. From Figure 1, impact of inclusiveness comprized situational awareness, innovation and business continuity. However, from the findings, the impact of inclusiveness on resilience in TMOs comprizes innovations, time and cost savings and quality enhancement. These were deduced from the impact of inclusiveness identified from case study 1 (as presented in Table 1). For instance, time and cost savings were identified from the following impact of inclusiveness on resilience; (a) clarity, trust, coordination, unveil hidden traits required to manage critical incident, (b) enabling endurance by the overall team to ensure readiness and reduction, (c) motivating to promote innovation and ensure response, (d) promoting experience sharing to ensure readiness and reduction, (e) promoting continual monitoring to identify disruptions in order to ensure readiness and reduction. Innovation was identified from the following impact of inclusiveness on resilience; (a) motivating to promote innovation and ensure response and (b) adopting alternative unplanned innovative solutions whilst maintaining quality requirement to ensure response whilst quality enhancement was identified from the following impact of inclusiveness on resilience; (a) promoting 
tolerance and adjusting to ensure response and vulnerability reduction whilst maintaining quality requirement and (b) adopting alternative unplanned innovative solutions whilst maintaining quality requirement to ensure response impacts.

These are presented in Figure 2 (an updated version of Figure 1). The common impact to organizational and TMO resilience however, is innovation. Inclusiveness impacts innovation in organizational resilience through the support in training (Yilmaz et al. 2015) it provides for the organizational members whereas inclusiveness impacts innovations in TMO through motivation and experience sharing.

The time and cost savings and quality enhancement identified within TMOs can be related to business continuity in permanent organizations however, their impacts differ. For instance, organizational resilience captures business continuity as the capability of the organization to continue delivery of products or services at acceptable predefined levels following a disruptive incident (ISO 22301:2012: Braes and Brook 2010). Hence, focussing on direct impact and the long-term benefits, whereas cost and time savings and quality enhancement aim to address the short-term benefits within TMOs given their spans but has indirect impact and the potential to ensure business continuity with the TMO client.

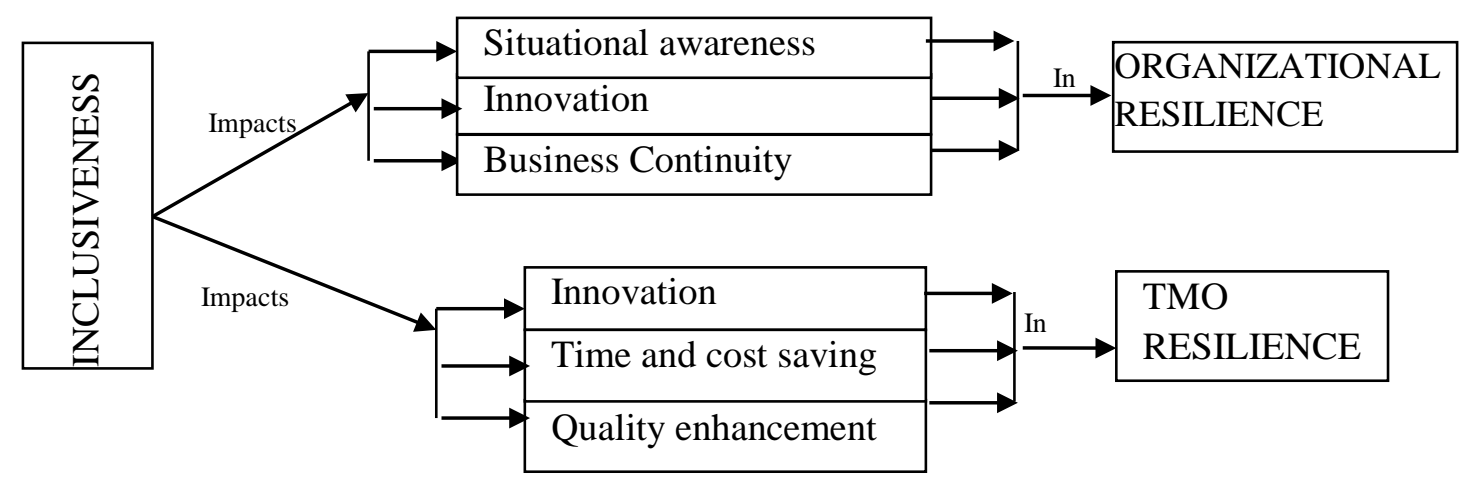

Figure 2. Developed framework for the impact of inclusiveness on resilience

\subsection{CONCLUSION}

Inclusiveness has been identified to positively impact resilience in TMO. The specific impacts such as innovation, time and cost saving and quality enhancement are identified. This clearly reveals the different impact it has on TMO to organizational resilience. The identified impact shows the importance and the need for TMOs to take time out to promote inclusiveness given the main challenge being time limitations. It has been identified that the benefits of promoting inclusiveness in TMO supersedes the extra time spent on it within construction. 
Theoretically, this research reveals the exact consequence of inclusiveness on resilience and the synergy between them. Practically, this research creates the awareness on the need for TMOs to promote and ensure inclusiveness especially during disruption management.

\section{REFERENCES}

Baccarini, D. (1996). “The concept of project complexity—a review”. International Journal of Project Management, 14(4), pp.201-204.

Benard, B. (1995). Fostering Resilience in Children. ERIC Digest.

Benard, B. (2004). Resiliency: What we have learned. San Francisco: WestEd.

Braes, B. and Brooks, D. (2010). Organizational resilience: a propositional study to understand and identify the essential concepts.

Fiori, C., and Kovaka, M. (2005). "Defining megaprojects: Learning from construction at the edge of experience". In Construction Research Congress 2005: Broadening Perspectives (pp. 1-10).

Gibson, R. (2015). A Practical Guide to Disruption and Productivity Loss on Construction and Engineering Projects. John Wiley \& Sons.

ISO022301. (2012). Business Continuity Management. https://www.bsigroup.com/en-GB/iso22301-business-continuity/

Janssens, M., and Zanoni, P. (2014). "Alternative diversity management: Organizational practices fostering ethnic equality at work". Scandinavian Journal of Management, 30(3), 317-331.

Kahn, W. A., Barton, M. A., and Fellows, S. (2013). "Organizational crises and the disturbance of relational systems". Academy of Management Review, 38(3), 377-396.

Kreiner, K. (1995). "In search of relevance: Project management in drifting environments". Scandinavian Journal of Management, 11(4), pp.335-346.

Lin Moe, T., and Pathranarakul, P. (2006). "An integrated approach to natural disaster management: public project management and its critical success factors". Disaster Prevention and Management: An International Journal, 15(3), 396-413.

Lok, P., Westwood, R., and Crawford, J. (2005). "Perceptions of organizational subculture and their significance for organizational commitment". Applied Psychology, 54(4), 490514.

McManus, S.T. (2008). Organizational resilience in new zealand (Doctoral dissertation, University of Canterbury).

Pateman, C. (2014). Sexual contract. John Wiley \& Sons, Ltd.

Pearson, J. (n.d.). "Sense of Belonging-Impact on Resilience".

Qazi, A., Quigley, J., Dickson, A. and Kirytopoulos, K. (2016). "Project Complexity and Risk 
Management (ProCRiM): Towards modelling project complexity driven risk paths in construction projects". International Journal of Project Management, 34(7), pp.11831198.

Ryan, A. M., and Kossek, E. E. (2008). "Work-life policy implementation: Breaking down or creating barriers to inclusiveness?". Human Resource Management, 47(2), 295-310.

Seville, E., Brunsdon, D., Dantas, A., Masurier, J. Le, Wilkinson, S., \& Vargo, J. (2006). "Building Organizational Resilience : A New Zealand Approach".

Sutcliffe, K. M., and T. J. Vogus. (2003). Organizing for Resilience. In Positive Organizational Scholarship, edited by K. Cameron, J. E. Dutton, and R. E. Quinn, 94110. San Francisco, CA: Berrett-Koehler.

Vacanasa, Y., Themistocleousa, K., Agapioua, A., and Hadjimitsisa, D. (2015, June). "Building Information Modelling (BIM) and Unmanned Aerial Vehicle (UAV) technologies in infrastructure construction project management and delay and disruption analysis”. In Third International Conference on Remote Sensing and Geoinformation of the Environment (pp. 95350C-95350C). International Society for Optics and Photonics.

Vogus, T. J., and Sutcliffe, K. M. (2007, October). “Organizational resilience: towards a theory and research agenda”. In Systems, Man and Cybernetics, 2007. ISIC. IEEE International Conference on (pp. 3418-3422). IEEE.

Yilmaz Borekci, D., Rofcanin, Y., and Gürbüz, H. (2015). “Organizational resilience and relational dynamics in triadic networks: a multiple case analysis”. International Journal of Production Research, 53(22), 6839-6867. 